
\title{
$\begin{array}{ll}\text { Research Square } & \begin{array}{l}\text { Preprints are preliminary reports that have not undergone peer review. } \\ \text { They should not be considered conclusive, used to inform clinical practice, } \\ \text { or referenced by the media as validated information. }\end{array}\end{array}$
}

\section{A Study on Intelligent Grinding Systems With Industrial Perspective}

Ramesh Kuppuswamy ( $\sim$ Ramesh.kuppuswamy@uct.ac.za )

University of Cape town https://orcid.org/0000-0002-5718-6083

Fungai Jani

University of Cape Town

\section{Samiksha Naidoo}

University of Cape Town

Quintin Jongh

University of Cape Town

\section{Research Article}

Keywords: intelligent grinding system, grinding process prediction, condition monitoring, sensors in grinding, real time-based grinding

Posted Date: April 16th, 2021

DOl: https://doi.org/10.21203/rs.3.rs-412534/v1

License: (c) (i) This work is licensed under a Creative Commons Attribution 4.0 International License. Read Full License 


\section{Abstract}

The digitization thrust on high value manufacturing and services opens-up new opportunities for ensuring; total system uptime, reliability, and efficiency particularly for mission-critical high value assets. The digitization process evolves intelligent manufacturing systems (IMS) which transforms maintenance into predictive reliability for achieving consistent quality throughout manufacturing process. This article unveils the intelligent grinding systems (IGS) for challenging grinding applications. For a more in-depth understanding and analysis of an entire intelligent grinding system, particular aspects within the system were discussed. These include Grinding Models, Process Design Algorithms, Process Monitoring, Process Control, Feature Extraction and Feature Correlation engines. The main focus, especially in the early 2000s, was mainly database development and parameter selection, which then shifted to process monitoring and control as particular technology advances were made. In the various goals that were investigated, it was evident that researchers were aiming for an online real-time system. This notion was driven by the advances in artificial intelligence and improved monitoring sensors, for example, acoustic emission sensors and even other unusual sensors like microphones for more economical and improved data collection and analysis. Although tremendous strides have been made, a substantial amount of work is still required in achieving a fully-fledged real-time intelligent grinding system. The comprehensive findings on IGS system concludes that the real time process update has been improved from few hours to milliseconds.

\section{Introduction}

The digitization thrust on high value manufacturing and services opens-up new opportunities for ensuring; total system uptime, reliability, and efficiency particularly for mission-critical high value assets. Past approaches such as preventive maintenance and reactive "fail-and-fix" methods are no longer adequate to meet the increasingly higher operational availability at an affordable cost. Also, maintaining a consistent quality in manufacturing remains as a daunting challenge as the manufacturing processes are subject to vary continuously. Use of intelligent manufacturing systems (IMS) aim to transform maintenance into predictive reliability so that a consistent quality can be maintained throughout manufacturing process. This article enumerates how the intelligence was applied to grinding process to evolve intelligent grinding systems (IGS). The study has revealed that the development of intelligent grinding system has started as early as 1985 , however since the start of 4th Industrial revolution a new momentum on this subject was apparently seen. The growth phase of Intelligent grinding system has been grouped into four major phases which are:

i. Grinding process monitoring and application of fuzzy logics on grinding process monitoring

ii. Acoustics-sensor based grinding process monitoring and statistical computation of wheel work process parameters for understanding the grinding failures.

iii. Sensor integration to grinding wheel towards development of an intelligent grinding wheel and use of RF signals for grinding process monitoring. 
iv. Real time-based grinding process monitoring and failure prediction using data driven models.

Shown in Fig. 1 is the chronological order of IGS development against the response time for process correction.

While the research developments in the IGS have a huge track record the successful application of IGS system to the industries are limited. Most of the past developments are confined to a specific application and hence the IGS is limited to a narrow range of applications. The bottleneck issues and research need of the IGS are summarized from the main protocols and are listed below.

- Physics-based approaches provide a reliable and accurate estimate of all modelling options by estimating the remaining useful life of the grinding wheel using a mathematical representation of the physical behavior of the degradation processes. However, the mathematical modelling does not account the dynamics of the wheel-work interface conditions.

- An extensive knowledge of the system/process behavior is a pre-requisite to improve the accuracy of prediction.

- The data driven model offer several weaknesses and the main observations are;

- Neural network methods require large data for ensuring the accuracy of prediction.

- Fuzzy logic rules are developed manually using the logics.

- Wiener process model is limited to Gaussian and linear system and the gamma process model is limited to monotonic degradation.

- Proportional hazard modelling (PHM) assumes that covariates are not dependent to each other. - Hidden Markov model (HMM) is limited to gaussian process.

- Prognosis methods viz. The determination of the probability density function (PDF) is facilitated by the model-based technique, which accounts for all the related variables as distributions, therefore enabling an accurate forecast of the useful life of the grinding wheel. While enumerating confidence, precision and accuracy, assessing uncertainty due to process and measurement noise are aspects well within the capabilities of the model-based technique.

- After understanding the broad challenges associated with the intelligent grinding system attempts were made to understand the past successful findings and its limitations. They are grouped into various subheadings such as: theorical and experimental based grinding models, expert grinding system, adaptive control based grinding system, fuzzy-logic based grinding system, neural network based grinding system and grinding process monitoring and control (see Fig. 2). This research article makes a comprehensive study of the all the past developments on IGS to better understand the developed systems and its merits and disadvantages. 


\section{Past Developments Towards Building An Intelligent Grinding System}

\section{- GRINDING MODELS - ANALYTICAL}

Past research endeavor on grinding model uses the various grinding parameters such as: grinding energy, grinding forces, power flux, grinding ratio, surface finish, Rt/Ra ratio, Residual stress, grinding temperature either directly or indirectly and put into use for the grinding process optimization. Grinding models such as: (i) analytical and simulation models and (ii) experimental based models were built for process monitoring. Shown in Fig. 3 is the grinding models preparations algorithm for experimental and theoretical grinding models.

Grinding burn was measured as a combination of grinding power and standard deviation of $A E_{r m s}$ signals and the findings has a significant correspondence with the grinding wheel sharpness conditions. It should be noted that grinding power increases as the grain engagement undergoes rubbing, plowing, and cutting conditions at the contact zone and hence the power as well as $A E_{r m s}$ signal found to have variations [1]. Another finding suggests the use of $A E_{r m s}$ signals with high sampling rate $2.5 \mathrm{MHz}$ and compared with the ground surface texture results. It was observed that grinding burn has a correlation with $A E_{r m s}$ frequency domain analysis [2]. Grinding burn was also measured in terms of grinding burn occurrence time for a newly dressed grinding wheel at different grinding conditions. The time data was then analyzed using the artificial neural network to establish the grinding burn phenomenon [3]. Attempts were also made to determine the abnormalities of wheel-work interface conditions in terms of $A E_{r m s}$ signals [4]. A recent research article outlays the use combination of wheel work interface signals using dynamometer, accelerometer and acoustic sensor and the signals were grouped using wavelet theory for grinding burn feature extraction and deep learning technique was adopted for grinding burn feature correlations [5]. Not long ago, a new optical sensor system was integrated into a grinding machine, making it possible to take measurements for quality assurance, optimization of the grinding process and reduction of setting-up and grinding time [6]. Table 1 list down the various analytical grinding models that enables to build a intelligent grinding system. 
Table 1

List of various analytical grinding models that enables to build an intelligent grinding system.

\section{Ref. Past findings}

[1] This work establishes grinding burn model in a surface grinding operation using two types of steel, three grinding conditions and an Al203 vitrified grinding wheel. Grinding burn is equated to a parameter which is the product of power level and acoustic emission standard deviation.

\section{Assessment}

Variation in grinding power is less for a minor change of the grinding wheel conditions. However, a distinct variation in acoustic signals is widely noted. The high dispersion of the acoustic emission RMS level associated to the high-power consumption confirms loss of grinding wheel sharpness. Such method of IGS system is dedicated to a specific application.

[2] This article suggests the use of acoustic emission signals collected at high sampling rate $(2.56 \mathrm{MHz})$ and the values are correlated to the grinding burn using the frequency analysis.

[3] This article uses the time of the occurrence of grinding burn during the cylindrical plunge grinding of steel which is a measure of grinding burn.

[4] This study developed an acoustic emission (AE) monitoring system that is able to detect abnormalities by comparing the pre-established acoustic emission signals for good and bad conditions.

[5] In this article, an intelligent grinding burn detection system that consists of processing of grinding signals, extraction of signal features, selection of optimal feature subset, and classification of grinding burn is presented. A large number of preliminary features in time domain and frequency domain are extracted after wavelet packet decomposition and ensemble empirical mode decomposition. The competitiveness of a deep learning network that was used to produce the grinding burn classification model, has been measured using various machine learning models.

[6] This finding suggests the use of a new optical sensor system integrated into a grinding machine, to take measurements for quality assurance, optimization of the grinding process.
Although this method is easier to build the IGS system, the large data collection occupies too much of system memory.

This method of building IGS is applicable to a very specific condition only.

This method of building IGS enable to establish the extreme conditions either good or bad grinding wheel conditions and hence prediction of process behavior is not feasible.

This paper presents a viable IGS tool but confined to one parameter grinding burn only. Therefore, this method may not be suitable for thermally insensitive materials.
This method of IGS uses both static and dynamic grinding conditions of the grinding process and uses the statistical factors for process prediction.

\section{- GRINDING MODEL-EMPIRICAL}

Although experimental models were only tested within specific conditions, they extensively illustrated the actual or physical grinding situation, necessitating a huge database to store all the experiments' 
outcomes. However, use of experimental based empirical model has been put into use in the early stages of intelligent grinding system that avoid fail and fix situations. Table 2 lists down the few previously developed empirical models.

Table 2

List of various empirical grinding models that enables to build a intelligent grinding system.

\begin{tabular}{|c|c|c|}
\hline Ref. & Past findings & Assessment \\
\hline [7] & $\begin{array}{l}\text { The Werner's Specific Force model was revised and validated } \\
\text { and modified for several specific grinding processes to } \\
\text { estimate grinding forces and specific energy. }\end{array}$ & $\begin{array}{l}\text { The revised method better } \\
\text { include the wheel-work } \\
\text { interface conditions and } \\
\text { improves the accuracy } \\
\text { especially for high efficiency } \\
\text { deep grinding. As a result, } \\
\text { IGS effort building with the } \\
\text { revised grinding force model } \\
\text { has better accuracy. }\end{array}$ \\
\hline [8] & $\begin{array}{l}\text { Consistent force data was extracted from a neatly designed } \\
\text { set of experiments that also involved signal to nose ratio and } \\
\text { orthogonal rays, using an empirical approach that was taken } \\
\text { to develop a grinding force model for aerospace alloys. } \\
\text { Multivariate analysis was utilized in acquiring a set of } \\
\text { empirical models for superalloy CMSX, with regards to } \\
\text { force, considering process parameters that included wheel } \\
\text { diameter, feed rate, wheel speed and depth of cut. }\end{array}$ & $\begin{array}{l}\text { This is fairly accurate but the } \\
\text { IGS system built using this } \\
\text { input is applicable only for } \\
\text { the experimented application. }\end{array}$ \\
\hline [9] & $\begin{array}{l}\text { Three key points are considered in this research, namely; } \\
\text { machine tool conditions, process parameters and dynamic } \\
\text { processing in an attempt to develop a dynamic force model } \\
\text { empirically, to monitor its variation. }\end{array}$ & $\begin{array}{l}\text { The distinct advantage on } \\
\text { this research is the use of } \\
\text { grinding dynamics on } \\
\text { grinding force assessment } \\
\text { but the IGS built using this } \\
\text { info is limited to the specific } \\
\text { experimented application. }\end{array}$ \\
\hline
\end{tabular}

\section{- GRINDING MODEL-NUMERICAL}

As the advances of numerical techniques and computational processing units come to the fore, the Finite Element Method (FEM) saw an increase in its application in modelling various aspects of the grinding process. The numerical models enable as a building block for formulation of an appropriate intelligent grinding system. A past research attempt unveils how a numerical model is used to compute the grinding temperature and strain-rate effects at the wheel-work interface [10]. 
Table 3

enumerate the notable numerical models that support the building of a intelligent grinding system.

\section{Ref. Past findings}

[10] The developed numerical model helps to compute the grinding temperature and strain-rate effects at the wheel-work interface

[11] This research is centered on a finite volumes thermal model with explicit representation of the grinding wheel and workpiece movements to determine temperature distribution and heat affected zones within the workpiece in each case.

[12] A numerical simulation technique has been developed to generate the grinding wheel topography using square pyramidal grits.

\section{Assessment}

The findings on cylindrical grinding process are suitable while using a CBN grinding wheel on $100 \mathrm{cr} 6$ bearing steel workpiece.

The findings on grinding temperature and heat affected zone enable to determine grinding induced residual stress and grinding burn and thus act a s a building block for intelligent grinding system

The theoretical findings on grinding wheel topography enable to compute the remaining useful life of grinding wheel which is an essential element for an intelligent grinding system

This research when compared with the triangular heat source model improves the accuracy by nearly 2 times.

This research enables to theoretically compute the expected surface finish in a grinding process and the output is useful to build an intelligent grinding system

[14] Using kinematic simulation to accurately model workpiece-wheel interaction, a wheel topography can be generated that allows an algorithm to be used to classify active abrasive grains and their attack angle. grinding wheel-work temperature with inclusion of anti-heat source which are abrasives and some lements of bond material. Also the numerical model is verified using the K-type thermocouple.

\section{- GRINDING MODEL-FUZZY LOGIC}

Fuzzy logic was introduced by incorporating both incredibly complex, non-linear analytical grinding process models and knowledge-based linguistic rules. This process allowed fuzzy rules to be made, which meant that systems that were generally difficult or too ambiguous to model finally had a solution. This type of system depended on a combination of a hefty number of complex theoretical grinding equations and the experts that had the necessary knowledge. Data storage was a non-negotiable necessity as it was required to store all the analytical knowledge, linguistic rules, and fuzzy rules. Furthermore, not all rules were qualitative, and there was a significant presence of quantitative reasoning which provided a good balance. Table 4 highlights the notable research accomplishments that uses the fuzzy logic for building the intelligent grinding system. A rule-based algorithm is a natural extension of fuzzy logic modelling and put into use for managing the grinding process. This kind of algorithm is essentially a conditional statement that stipulates an action that is supposed to occur under circumstances. Some researchers explain that it is based on an expert's knowledge referred to and executed in the form of the "if-then" rules. Some advantages include modularity, homogeneousness, and 
naturalness. Still, it can be challenging to make rules without exact exceptions, and knowledge attainment is often a hindrance to the process's success as a whole.

Table 4

Notable research accomplishments that uses the fuzzy logic for building the intelligent grinding system.

\begin{tabular}{|lll|}
\hline Ref. & Past findings & Assessment \\
\hline [15] & $\begin{array}{l}\text { The study unveils how fuzzy logic, neural networks, and } \\
\text { evolutionary algorithms (EA) are used for modeling complex } \\
\text { grinding processes and finding optimal process conditions. }\end{array}$ & $\begin{array}{l}\text { The built IGs system has } \\
\text { helped to minimize the } \\
\text { grinding cost, cycle time, and } \\
\text { maximize process control. }\end{array}$ \\
\hline [16] $\begin{array}{l}\text { When the grinding load exceeds the strength of the retaining } \\
\text { bond bridges, grains drop out, and the ground surface } \\
\text { texture are also scratched. In this study, a dynamic } \\
\text { threshold-based fuzzy adaptive control algorithm that uses } \\
\text { the spindle current as a parameter was devised to avoid } \\
\text { scratches on the workpiece. }\end{array}$ & $\begin{array}{l}\text { The grinding process that } \\
\text { uses the fuzzy based } \\
\text { adaptive control avoid } \\
\text { scratches on the workpiece } \\
\text { and reduces the form error } \\
\text { with enhanced grinding } \\
\text { efficiency. }\end{array}$ \\
\hline $\begin{array}{l}\text { This paper identifies grinding burn using highly sensitive } \\
\text { acoustic emission (AE) techniques. The wavelet packet } \\
\text { transform is used to extract features from AE signals and } \\
\text { fuzzy pattern recognition is employed for optimizing } \\
\text { features and identifying the grinding status. }\end{array}$ & $\begin{array}{l}\text { The results suggests that the } \\
\text { accuracy of grinding burn } \\
\text { recognition is satisfactory. }\end{array}$ \\
\hline
\end{tabular}

\section{- GRINDING MODEL - NEURAL NETWORKS}

Through knowledge accumulation sessions, a neural network progressively develops a model of the grinding process. When network weights are strengthened by positive outcomes or otherwise weakened due to a negative outcome, the neural network makes necessary adjustments in its model according to the interpretation of outcomes. This behavior supports the notion that we can indeed acknowledge that artificial neurons mimic neurons' action in a brain. From the research that applied neural network algorithms, it was evident that these algorithms had a few advantages. They are easier to develop and implement as compared to rule-based algorithms and they do not require an expert user. Table 5 illustrates major findings of IGS that uses neural network techniques. 
Table 5

Past Intelligent grinding systems that uses neural network techniques.

\section{Ref. Past findings}

[18] Surface roughness and grinding forces are the required predictions in this ANN model, which utilizes an acoustic emission (AE) sensor. One model was trained using grinding parameters only, while one used both $A E$ and grinding parameters.

[19] This study applies artificial intelligence technology on grinding process to attempt to learn the experiences of auditory recognition of experienced operators. It uses a microphone embedded in the grinding machine to collect audio signals during the grinding process and extracts the most discriminated feature from spectrum analysis.

[20] This study uses both physics-based model and grinding process dynamics to build the technology of intelligent grinding.

[21] This is a review paper and presents the theoretical and experimental models used, process design algorithms, expert systems, artificial intelligent algorithms, fuzzy logic and neural network algorithms, process monitoring and control, and in particular artificial intelligence control systems.

[22] This paper describes the structure, content, and relations employed in an intelligent grinding database developed to provide only selective and/or optimal data to the operator. The intelligent database was constructed in MS Access with Visual Basic support code.

[23] An advisory system was proposed in this paper, which combines knowledge-based rules with analytical models to generate fuzzy rules using a unique and novel rule generation procedure.

[24] The assessment of the grinding wheel condition but particularly its cutting ability, was done by a combination on neural and fuzzy rules. Signals from the multiple sensors were handled by a back propagation network for feature selection.

\section{Assessment}

The results also showed that the AE signals act as an additional input parameter in addition to the grinding parameters and could significantly increase the efficiency of the neural network in predicting the grinding forces and the surface roughness.

The results show that the use of Al using the microphone signals achieve an accuracy of $97.44 \%$.

A significant matching between the theoretical and practical information was noted.

The review was done in 2007 and the review does not include the recent developments

A useful skeleton of IGS was unveiled.
The implementation of the system shows that the system can lead to the optimal design of a grinding process very effectively even with a large number of process parameters.

The output lays a good learning platform for building an IGS.

[25] Al techniques that focus on 3 aspects, namely; monitoring, control and optimization were employed in this particular supervision system, to reduce waviness errors, optimize material removal rate, reduce surface roughness and out-of-roundness errors. 


\section{Ref. Past findings}

[26] This paper describes how adaptive control can be used in a generic intelligent grinding control system, thereby building intelligence into the system.

[27] Both the process parameters and AE signals were fed through a gaussian neural network, and trained via memory and also via a model structure that was not quantified previously, but instead, was determined from the data, to estimate required process output.

[28] Feature extraction and feature selection were used using the acoustic emission signals for grinding operations. The AE signals were processed by autoregressive modeling or discrete wavelet decomposition for feature extraction, and then the best feature subsets are found by three different feature selection methods: ant colony optimization (ACO)-based method and the sequential forward floating selection method.

[29] This research shows how a Intelligent testing system was applied to predict the early failure of cutting tools.

\section{Assessment}

The developed system enables to consistently achieve the workpiece size and surface integrity

In this research an on-line estimation of surface roughness during grinding was established.

The test results illustrate the effectiveness of feature extraction and feature selection methods.
[30] With grinding burn features as the process outcome to be investigated, the chosen signal processing tool was Hilbert-Haung transform (HHT) to process raw $\mathrm{AE}$ and accelerator signals. This multi-sensor system, included voltage and current signals as well.

[31] Hidden Markov Models (HMM) are developed in this study for predicting grinding wheel conditions in the autofeed surface grinding process using Acoustic Emission $(\mathrm{AE})$ signatures captured during the grinding operation was correlated with the tool conditions using Baum-Welch and Viterbi algorithms. HMMs proposed in this study are integrated with the K-means clustering such as: 'sharp', 'intermediate' and 'worn out'.

[32] This research paper introduces Support Vector Machine (SVM) to classify different wheel situations, which proved to be very effective with use of the supplied data.

[33]
This research paper describes the classification of grinding contact, collision and burn using AE signals, which was enabled by a support vector machine.
The statistical based intelligent testing system for cutting tools demonstrates an industrial application.

The application of HHT to acoustic emission signals in grinding burn detection is found to have great potential for building an IGS.

It is observed that HMM models built with $\mathrm{AE}-\mathrm{RMS}$ feature predicted the grinding wheel conditions with good accuracy.
The grinding process monitoring illustrates how effective SVMs can be in determining wheel redress-life.

The accuracy of the developed IGS system largely depends upon how the SVC is applied to classify the acoustic emission signals. 


\begin{tabular}{|cll|}
\hline Ref. & Past findings & Assessment \\
\hline [34] & $\begin{array}{l}\text { An adaptive network-based fuzzy inference system that } \\
\text { was developed, generates signals that assist in } \\
\text { classifying surface roughness and vibrations in } \\
\text { cylindrical grinding. Unique neuro-fuzzy parameters were } \\
\text { employed to improve the online monitoring capability of } \\
\text { the system during the training process. }\end{array}$ & $\begin{array}{l}\text { A prediction accuracy of } 99 \% \\
\text { was achieved after experimental } \\
\text { validation was carried out. }\end{array}$ \\
\hline [35] & $\begin{array}{l}\text { Thermal deformation derived from measured grinding } \\
\text { force, was the premise by which this particular IGS was } \\
\text { developed, in order to improve size accuracy. }\end{array}$ & $\begin{array}{l}\text { With grinding experiments, it is } \\
\text { confirmed that the developed } \\
\text { intelligent grinding system can } \\
\text { improve the size accuracy } \\
\text { successfully. }\end{array}$ \\
\hline
\end{tabular}

\section{- GRINDING MODEL - BASED ON PROCESS MONITORING}

The issue of copious amounts of data led to research in a more systematic and integrated system that allowed an intelligent advisory system to control the process for optimum grinding process variables that met particular requirements. It is acceptable to consider that a lot of the knowledge resided principally with operators. Still, the extensive usage of sensors and instrumentation that gather various process information has provided an opportunity to collect and store such data to be used intelligently. Table 6 summarizes the modelling-based grinding process monitoring. 
Table 6

Summary of past research on IGS built using the grinding process monitoring.

\section{Ref. Past findings}

[36] A dynamic, intelligent control model of grinding was devised using the grinding quality data and analysis.

[37] The topic of intelligent control and optimization techniques has been reviewed by this research paper, including the incorporation of these techniques into computer numerical controls (CNCs)

[38] In this research paper, the amplitude and frequency changes for $A E$ signals enabled the determination of the grinding wheel life, while the monitored dressing process produced a grinding wheel with constant quality.

[39] The main task of the grinding monitoring system is the detection of disturbances and the grinding cycle optimization based on the $A E$ and power signal.

\section{Assessment}

The result has enabled to build control chart of grinding quality along with the prediction of grinding quality.

Two main trends are evidenced in the development of Al technologies in grinding: desktop systems to assist tool and parameter selection and self-optimizing systems integrated within the machine controller.

Contact between the grinding wheel and the workpiece was successfully detected with the $A E$ signal, which means that this method is effective as a gap eliminator.
The influence of different dressing parameters on the AE-signal has been investigated through a development of a dressing monitoring system. Reliable data acquisition techniques, which make a continuous scanning of such wide bandwidth signals have applied.
[40] In the process of automation and intelligent grinding, using related variety of force, vibration, displacement sensor to monitor the grinding process, timely adjustment of machine tool, grinding quality and efficiency can be improved.
The efficiency of grinding process was improved within a short time.

\section{- GRINDING MODEL - ADAPTIVE CONTROL BASED GRINDING SYSTEMS}

The adaptive control algorithm has been used extensively in the grinding process. An adaptive system measures a certain index of performance using the inputs, the states, and the outputs of the adjustable system. The adaption mechanism works in such a way that, it tries to make necessary the adjustment was possible within the system, before it decides to provide supplementary inputs that are similar to the original inputs, to obtain required results.

The potential of adaptive control systems to handle complex problems was stifled because the manipulation of process parameters was hinged on convergence which was not in favor of the adaptive control systems principles. The adaptive control-based grinding avoids the failure zone, and this extends the life of the grinding system. However, often this method may not fully exploit the system capability. Table 7 illustrates major findings of IGS that uses adaptive control-based grinding systems. 
Major findings of IGS that uses adaptive control-based grinding systems.

\section{Ref. Past findings}

[41] As it is critical to be able to control the grinding force during a grinding process, a sensor is always necessary, that measures the force between the workpiece and the tool. Simultaneously, the data that is extracted must be sent to the adjustment controller, in order to cater for different process conditions.

[42] The theory of automatic force control was merged with a ring-shape 6-axis force sensor, that also included a failsafe structure and compliance device, in order to automatically control the movement of the grinder to ensure a constant grinding force.

[43] The limitations of knowledge-based systems were stretched by the use of rule-based reasoning (RBR) which utilized previous knowledge and understanding. However rough set RBR is used for cam numerical control (NC), for a cubic boron nitride (CBN) grinding wheel.
Assessment

Good grinding results are produced from the experiments with such methods.
This technique grinds the surface without any information about surface configuration.
In the system, the rough set RBR is used to assess the dressing parameters. A series of experiments have been accomplished by CNC8312A NC camshaft grinder.

There also several past research on development of intelligent grinding wheel by embedding a sensor in the grinding wheel and the wheel-work interface phenomenon s observation through radiofrequencycontrolled system controller. The data from AE and power sensors, that made an 'intelligent' grinding wheel was processed and transmitted using a DSP-based telemetric module attached to the wheel face. The piezoceramic sensor for example was embedded in the aluminum core of the wheel fitted with diamond abrasive segments on its periphery. The sensors were equally spaced near the wheel bore to accurately measure the instantaneous normal force [44].

A similar intelligent grinding wheel method was also attempted on a cylindrical grinding process and experimentally validated. Priority was placed upon the use of these types of sensors as they are able to detect various issues in the grinding process to allow optimization of the grinding cycle in real-time [45].

\section{Discussion On Various Intelligent Grinding Systems}

\section{Previous Intelligent Grinding Systems}

In the early stages of IGS development a greater cooperation between machine tool builder and university was noted. The intelligent database was developed in MS Access with Visual Basic support code. This database involved Cycle Data which consisted of Reference Cycle Data that remained unchanged, Active Cycle Data, which provide temporary storage of current data, and Optimized Cycle Data for adapted data. The temporary data was stored in MACRO-B of a CNC controller. An IGPS (Intelligent Grinding Parameters Selector), which used a combination of Case-Based Reasoning (CBR) and Rule-Based Reasoning (RBR), allowed the database to be useful in choosing initial parameters that had safety as a priority. Stable 
optimal grinding conditions are possible through adaptive control because it manipulates given parameters when the need arises to compensate for deviations in various aspects of the grinding process, for example, the operating environment. Setup time was still an inherent issue, but the system's assistance in parameter selection was a good step in the right direction. There is still a lack of flexibility as it was often necessary to avoid wheel changes for more consistent results [35]. Nearly in the same period attempts were made to automatically establishing the database by using information obtained through some sensors infused into the grinding process and the grinding results produced. Two different sensors (AE sensor, power sensor) for complementation and interaction and improving the reliability of the sensing system were used. As a result, the developed IGs system has enabled to directly establish the grinding wheel-work interface behavior in terms of grinding burn, chatter vibration, surface roughness deterioration and grinding ratio. Also, genetic algorithms and fuzzy reasoning were put into use to learn the relationship between the input and output from the grinding results. The monitoring system was not adequately integrated into the grinding machine to allow for real-time control, which did not enable adaptive control of the grinding process [45]. Early research endeavors on IGS suggests two methods (i) method of maintaining the desired grinding input parameter through comparison between the input and actual data called as "servo design" and (ii) method of grinding process control through monitoring the process behavior in terms of acoustic emission and power signal called as "response design" [45]. (see Fig. 4A\&B)

The servo-design aim to maintain the input parameter through a velocity/positional feedback arrangement and correction is made continuously. This method is acceptable for Intelligent machining system as the machining undergoes several directional changes and hence the chip thickness likely to vary at every directional change and accelerate the flank-wear. The chip thickness variation is given in terms of actual depth of cut $\left(\mathrm{a}_{\mathrm{e}}\right)$ in Fig. 4A. The effort towards maintaining a constant chip-thickness through varying the input parameters is beneficial to extend the tool life [47].

The response design takes into account of all the responses such as wheel-work interface behavior, machine dynamics, coolant conditions, wheel condition and the overall system as a whole. The response system also gives how the system failure is growing gradually and thus gives an opportunity to take early preventive actions. However, challenge lies on signal collection, filtering, noise separation and analysis. The response design is more suitable for the grinding processes. A typical AE rms signal for a normal state and abnormal state of grinding is given in Fig. 4B.

The efficiency of the "response design" is further improved through application of neural network and fuzzy logic-based systems combining the outputs of several sensors for grinding wheel condition monitoring during the grinding processes [24]. Several attempts were also noted on signal conditioning as it contains a mix of noise and signals by the application of back-propagation neural network method. The signal conditioning includes several hidden layers and number of hidden layers is decided by applying the weight pruning method. The signal analysis such as: Spectrum analysis, cepstrum analysis and wavelet analysis were extensively used for processing the signals (see Fig. 5). Both frequency and time analysis are extensively used for the signal processing. The fast Fourier transform (FFT) converts 
the time domain data into frequency domain data. While the time analysis helps to identify the failure progression, the frequency analysis helps to take preventive action by understanding the nature of event that takes place at the grinding wheel-work interfaces. The frequency domain study is further simplified while using the cepstrum analysis which clusters the different frequencies corresponding to components that exists in the rotating machine/system. The cepstrum plots are used to identify the conditions of the system (wheel-work interface) with help of frequency information in the acquired signals. Also, the power spectral density is often computed from the acquired signal. Several past attempts also suggest the use of power spectrum analysis, cepstrum analysis, higher order spectrum analysis and neural network analysis for rotating machines [49]. They revealed that cepstrum analysis is a very useful tool for detection families of harmonics with uniform spacing or the families of sidebands commonly found in rotating machines. Spectrum analysis has its own limitations as it can only be used for stationary signals [50]. Also, the advancement of Matlab make a significant use of wavelet transform analysis in the signal processing, which is more reliable, sensitive, and faster than spectrum analysis in prediction of grinding wheel failures.

Often the wavelet analysis is put into use in its Discrete wavelet transform (DWT) in which the signal is decomposed into two frequency sub bands such as low frequency band (approximate coefficients) and high frequency band (detailed coefficients) through high pass filters and low pass filters. Then the decomposed low frequency component of the signal will be again decomposed into approximate and detailed coefficients. This iteration will go on and at each step the approximate coefficient is considered as DWT. The wavelet feature, DWT analysis is much more efficient, less computation time and is reliable to identify small changes in $A E$ and current signals of the grinding processes for wheel failure. However, it is advisable to use a combination of MATLAB and ceptrum analysis to enhance the signal/noise ratio and to match the signal with the grinding sciences. In addition to the above statistical analysis is also widely used to fault information from the large data. Numerous investigations have been carried out in different area of fault detection using a set of statistical parameters as a feature extraction method. The statistical parameters such as mean, standard error, median, mode, standard deviation, variance, kurtosis, skewness, range, minimum, maximum, etc. have been widely used by the researchers on their studies on intelligent fault diagnosis. Apart from the signal conditioning it is also equally important to correlate the signals with grinding sciences. In order to that the intelligent grinding system us configured with two components which are (i) feature extraction engine and (ii) feature correlation engine. To digitize the grinding process, we normally deploy dynamometer to measure the grinding force, AE sensor to measure the acoustic signals close to the wheel work interface, accelerometer to pick up the vibration signals for ascertaining the grinding wheel-work stiffness and thermocouple or infrared camera to measure the wheel-work contact temperature (See Fig. 6). The measure of force signatures, AE signals, accelerometer input and thermal camera recordings do convey the wheel-work interface behavior. The higher grinding forces suggest the large, undeformed chip thickness which may alter the fracture mechanics, induce thermal damage, and control the residual stress magnitude. Table 8 consolidates how the measured and conditioned signals are connected to the grinding parameters and opens opportunities for better administration of the grinding process as well as prediction of grinding failure if any. 
Table 8

Influence of measured and conditioned signals on the grinding mechanism and processes.

\section{Details of Signals \\ Details of the affected grinding phenomenon}

\section{Force Signatures}

Tangential Increase of tangential forces is an indication of increased grinding energy. For a

Force (Ft) constant grinding conditions, if the tangential forces increase over a time it gives an indication that the ratio between rubbing: plowing and cutting is changing due to the dullness of the grinding wheel or due to wheel loading.

Normal Force Increase of normal forces is an indication of increased undeformed chip thickness.

$(\mathrm{Fn})$ However, for a constant grinding conditions the undeformed chip thickness is expected to remain same. The increase of normal forces over a grinding time indicates a change fracture mechanics due to the degradation of the grinding wheel.

\section{Acoustics Emission Signals}

$\mathrm{AE}_{\mathrm{rms}} \quad$ Acoustic emission signal is reflection of complete wheel-work interface phenomenon. Usually, the trend follow the normal forces and it is an indirect method determining the grinding wheel degradation.

\section{Accelerometer signals}

Displacement

- Velocity

- Acceleration

Thermal camera recordings
The information such as displacement, velocity and acceleration indicate the vibrational parameters at the accelerometer mounting area. Such information is mostly useful to establish a catastrophic failure of the tool (grinding wheel)

\section{Combination of two or more signals}

$\mathrm{F}_{\mathrm{t} /} \mathrm{F}_{\mathrm{n}}$ ratio The ratio suggests the wheel work interface friction and is an indication of thermal input to the ground surface.

Power flux This ratio of normal griding force to the contact area is termed as power flux. The value indirectly indicates the thermal input to the ground surface.

Grinding ratio

The value suggests the grinding wheel life and can be deduced with the degrading force and $\mathrm{AE}_{\mathrm{rms}}$ signals along with the number of components ground or volume of material ground. Few assumptions such $1 / 3$ of grain is protruding away from the grinding wheel and when the grinding wheel comes to end of life either the abrasive wear consumed the grain or the gaps between the abrasives or filled with the foreign (swarf) material. 
After feature extraction and creating a reference platform for a particular grinding process break-ingrinding test is conducted for a new workpiece and the test results are used for prediction of grinding process behavior and grinding wheel failure. Several techniques such as: decision tree technique, Artificial neural network, Support vector machines, K-Star algorithm and Bayesian network are used for feature correlation and grinding process prediction.

\section{- Decision tree technique:}

The decision tree selects a subset of the existing features without any transformation by representing the signal information in the form of tree. The decision tree can also be used as a classifier. A typical decision tree for a grinding process is shown in Fig. 7. The $A E_{r m s} /$ Force signals of a grinding process was analysed for different conditions such as abrasive wear, wheel loading, grain breakage and healthy grinding. Statical information such as standard error, kurtosis, median, mode, mean and range for the break-in-grinding process is compared with the feature extraction based statistical data and the griding wheel failure is predicted as shown in Fig. 7. The rectangular blocks indicate classes (condition of the grinding wheel). Based on the data input it was pre-fixed that when standard error is greater than $\mathrm{F}$ value it is classified as healthy condition, whereas, when the standard error is greater than A and less than/equal to $F$ value it is classified as abrasive wear condition and so on. The grinding wheel conditions (healthy, abrasive wear, grain breakage and wheel loading) are represented as leaves in the tree. These selected features are treated as an input to the classifiers such as SVM, ANN, Naïve Bayes, decision tree, and K-star models. Often the output of decision support tree is remodelled as confusion matrix. A typical confusion matrix for the grinding wheel failure which is a replacement of Fig. 7 is given in Table 9. The confusion matrix suggests how the results of break-in-test is accounted and tabled. N1, N2, N3 and N4 represents the number of $A E_{r m s}$ signatures that are closely resembled to the event within the break-intests. In some cases, some of the AErms signatures may lie in border areas of grinding wheel failure events and thus the classification accuracy can be calculated. Calculation accuracy is the ratio between total number good signatures which can be grouped into any of the expected wheel failures to the total number of signatures studied in the beak-in-tests. 
Table 9

Decision tree confusion matrix for statistical features of $A E_{r m s}$ signal

\begin{tabular}{|lllll|}
\hline $\begin{array}{l}\mathrm{P}=\text { Number of } \\
\text { healthy grinding } \\
\text { signatures within } \\
\text { the break-in-test }\end{array}$ & $\begin{array}{l}\text { Q= Number of } \\
\text { abrasive wear } \\
\text { signatures } \\
\text { within the break- } \\
\text { in-test }\end{array}$ & $\begin{array}{l}\mathrm{R}=\text { Number of } \\
\text { grain fracture } \\
\text { signatures } \\
\text { within the break- } \\
\text { in-test }\end{array}$ & $\begin{array}{l}\text { S = Number of } \\
\text { wheel loading } \\
\text { signatures } \\
\text { within the break- } \\
\text { in-test }\end{array}$ & $\begin{array}{l}\text { Total wheel failure } \\
\text { Signatures within } \\
\text { the break in test = } \\
\text { (N1 + N2 + N3 + N4) }\end{array}$ \\
\hline $\mathrm{N} 1$ & $\mathrm{X}$ & $\mathrm{x}$ & $\mathrm{x}$ & $\mathrm{P}=$ healthy \\
$\mathrm{X}$ & $\mathrm{N} 2$ & $\mathrm{x}$ & $\mathrm{Q}=$ abrasive wear \\
$\mathrm{X}$ & $\mathrm{X}$ & $\mathrm{N} 3$ & $\mathrm{X}$ & $\mathrm{R}=$ grain fracture \\
$\mathrm{X}$ & $\mathrm{X}$ & $\mathrm{X}$ & $\mathrm{N} 4$ & $\mathrm{~S}=$ wheel loading \\
\hline
\end{tabular}

\section{- Artificial neural network}

Artificial neural networks are modelled on the basis of biological neurons and nervous systems. They have the processing elements known as neurons, which perform their operations in parallel. ANN's are characterized by their topology, weight vector and activation functions. The connection between the neurons possesses the associated weight which is being multiplied to the incoming data/signal. ANN uses mathematical formulations to form a model and a neural network is used to learn patterns and relationships in data. An ANN is denoted by three elements, one is architecture which depicts the connection between neurons. Second is training or learning which determines the weights on the connections and the third one is activation function which is used to compute the output response of a neuron. A typical ANN consists of an input layer, hidden layer and output layer of neurons as shown in Fig. 8. The Activity of neurons in the input layer represents the raw signal/data, this signal is processed at neurons of hidden layer with the help of weights associated with the connections between input and hidden layers. Similarly, the output response of the neurons of the output layer depends on the activity of hidden layer neurons and weights of connection between hidden and output layers. For a grinding process a multilayer perceptron (MLP) neural network is often used to distinguish the grinding conditions, because the single layer perceptron network is only used for linearly separable classification of patterns. The grinding wheel in fault condition possesses a non-linear/non-stationary signal. Hence, the single layer perceptron network is not applicable for this study. MLP is an eminent class of neural networks and it is a unidirectional network with supervised learning and having back propagation algorithm which can be used to update the weights. This comprises of an input layer, one or more hidden layer and an output layer. In MLP networks, there exists a nonlinear activation function called logistic sigmoid function which is widely used to perform highly complex tasks. A typical MLP network for grinding wheel failure is given in Fig. 8.

In some case the intelligent grinding system also uses support vector machines, K-Star algorithm and Bayesian network and these are another method of representation of grinding wheel failures. The main 
purpose of a SVM is to create a classifier that reduces the structural risk that may occur due to empirical error as well as diminish the intricacy of a model, in order to achieve a good accuracy for previously unseen data. A least squares SVM was applied in classifying whether a grinding wheel was cutting air or actually cutting into the workpiece. The performance was satisfactory and was not significantly affected by surrounding environmental disturbances [51]. When SVM was applied to monitor tool condition by simply stating whether the tool was dull or sharp, the SVM which made use of cubic kernel function due to non-linearly separable patterns prevailed as the most superior classifier [52]. SVM seems to thrive in data driven modelling, as well as models with a limited number of samples [53]. Although limited in its application in tool condition monitoring, the K-Star algorithms works on the principle of entropy. By arbitrarily sifting through all the possible changes, the algorithm forms a basis by which one condition can be altered into another. Although a classification accuracy of $78.69 \%$ in a single point cutting tool is not as competitive as other classification models, the algorithm reveals potential for cost saving and efficiency in manufacturing [54]. Bayesian networks have been described as unique graphical models, in which its framework does not involve any cycles. This basically means that, any specific node cannot travel from its origin through the edges (which define the relationship between two nodes) in the correct manner and arrive back at its starting point [55]. In an example where a Bayesian network was used to infer the relationship between products and systems, it revealed its great potential in being able to find useful relationships between variables it had not encountered prior. The drawback however is the necessity for competently coded data, pertaining to the variables being investigated [56].

\section{Conclusion}

Grinding processes are among the most common industrial operations used in every day in industries. Therefore, process monitoring, and fault diagnosis of grinding operations are very important and useful to the industry. Although considerable research has been conducted in this field, there is still no clarity on which method of feature extraction and feature correlation is reliable, robust, accurate, inexpensive, automatic, practical and independent from the operating conditions. This research unveil a comprehensive research finding of past developed intelligent grinding systems and its tools. The research suggests that a combination of conventional signal processing and artificial intelligence methods are useful for building a intelligent grinding systems. Also, the IGS built using $A E_{r m s}$ signal is found to be cost effective methods when compared with other signals such as cutting force signal, current signal, etc. Furthermore, application of grinding science along with grinding feature selection and correlation are equally important to build a most useful IGS for industries. The research finds the widespread use of spectrum analysis, wavelet analysis and cepstrum analysis for signal collection and conditioning. Also, for both feature collection and break-in test methods such as: decision tree technique, artificial neural network, support vector machines, K-Star algorithm and bayesian network are found to be more practical, and accurate for building the intelligent grinding systems. The past research on grinding wheel fault diagnosis reveals that, statistical features have provided better classification efficiency in comparison with all other feature types. 


\section{Declarations}

\section{ACKNOWLEDGEMENT}

This project was supported by fund NRF GRANT: INCENTIVE FUNDING FOR RATED RESEARCHERS (IPRR) - South Africa through Reference: IFR150204113619 and Grant No: 96066. The views expressed and the conclusions drawn in this paper are those of the authors and cannot necessarily be attributed to the references.

Ethical Approval: The author(s) confirm that the paper has not been published previously in any form or language, that it is not under consideration for publication elsewhere and does not contain material which has been published previously. The results are presented clearly, honestly, and without fabrication, falsification or inappropriate data manipulation.

Consent to Participate: Not applicable

Consent to Publish: Not applicable

Authors Contributions: Fungai Jani: Investigation, Methodology, Writing - Original Draft, Samiksha Naidoo: Investigation, Conceptualization, Methodology, Validation, support writing-Original Draft, Quintin de Jongh: Investigation, Conceptualization, Methodology, Validation, support writing-Original Draft Ramesh Kuppuswamy: Supervision, Project administration, Resources, Validation and Investigation

Funding: This project was supported by fund NRF GRANT: INCENTIVE FUNDING FOR RATED RESEARCHERS (IPRR) - South Africa through Reference: IFR150204113619 and Grant No: 96066. The views expressed and the conclusions drawn in this paper are those of the authors and cannot necessarily be attributed to the references. 1

Competing Interests: The author(s) declared no potential conflicts of interest with respect to the research, authorship, and/or publication of this article.

Availability of data and materials: The authors confirm that the data supporting the findings of this study are available within the article.

\section{References}

1. P DeAguiar, J F G Oliveira (1999) Production grinding burn detection using acoustic emission and electric power signals. Scopus. https://repositorio.unesp.br/handle/11449/66028

2. P De Aguiar, P Willett, J Webster (1999) Acoustic emission applied to detect work-piece burn during grinding. ASTM International. https://doi.org/10.1520/STP15784S

3. R Deiva Nathan, L Vijayaraghavan, and R Krishnamurthy (1999) In-process monitoring of grinding burn in the cylindrical grinding of steel. J Mater Process Technol 91(1-3):37-42. https://doi.org/10.1016/S0924-0136(98)00408-7 
4. H Y Kim, S R Kim, J H Ahn, S H Kim (2001) Process monitoring of centerless grinding using acoustic emission. J Mater Process Technol 111(1-3):273-278. https://doi:10.1016/S0924-0136(01)00533-7

5. Guo W, Li B, Shen S, Zhou Q (2019) An intelligent grinding burn detection system based on two-stage feature selection and stacked sparse autoencoder. Int J Adv Manuf Technol 103(5-8):2837-2847. https://doi.org/10.1007/s00170-019-03748-5

6. Claus P Keferstein, Daniel Honegger, Hugo Thurnherr, Bernard Gschwend (2008) Process monitoring in non-circular grinding with optical sensor. CIRP Annals 57(1):533-536. https://doi.org/10.1016/j.cirp.2008.03.133

7. Vijay Kumar Mishra, Konstantinos Salonitis (2013) Empirical estimation of grinding specific forces and energy based on a modified Werner grinding model. Procedia CIRP 8:287-292. https://doi.org/10.1016/j.procir.2013.06.104

8. Qiang Liu, Xun Chen, Yan Wang, Nabul Gindy (2008) Empirical modelling of grinding force based on multivariate analysis. Journal of MaterialProcessing Technology 203(1-3): 420-430. https://doi.org/10.1016/j.jmatprotec.2007.10.058

9. Guo M, Li B, Ding Z, Liang S Y (2016) Empirical modeling of dynamic grinding force based on process analysis. Int J Adv Manuf Technol 86:3395-3405. https://doi.org/10.1007/s00170-016$8465-z$

10. Ali Zahedi, Bahman Azarhoushang (2016) FEM based modeling of cylindrical grinding process incorporating wheel topography measurement. Procedia CIRP 46:201-204. https://doi.org/10.1016/j.procir.2016.03.179

11. Janos Kundrák, Angelos P Markopoulos, Nikolaos E Karkalos (2017) Numerical simulation of grinding with realistic representation of grinding wheel and workpiece movements: a finite volumes study. Procedia CIRP 58:275-280. https://doi.org/10.1016/j.procir.2017.03.192

12. Chakrabarti S, Paul S (2008) Numerical modelling of surface topography in super abrasive grinding. Int J Adv Manuf Technol 39:29-38. https://doi.org/10.1007/s00170-007-1201-y

13. Lan S, Jiao F (2019) Modeling of heat source in grinding zone and numerical simulation for grinding temperature field. Int J Adv Manuf Technol 103:3077-3086. https://doi.org/10.1007/s00170-01903662-w

14. T A Nguyen, D L Butler (2005) Simulation of surface grinding process, part 2: interaction of the abrasive grain with the work-piece. Int J Mach Tools Manuf 45:1329-1336. https://doi.org/10.1016/j.jimachtools.2005.01.006

15. C W Lee (2000) Intelligent modeling and optimization of grinding processes. Dissertation, Purdue University

16. Li D, Xu M, Wei C et al (2012) A dynamic threshold-based fuzzy adaptive control algorithm for hard sphere grinding. Int J Adv Manuf Technol 60: 923-932. https://doi.org/10.1007/s00170-011-3661-3

17. Qiang Liu, Xun Chen, Nabil Gindy (2005) Fuzzy pattern recognition of AE signals for grinding burn. Int J Mach Tools Manuf 45(7-8): 811-818. https://doi.org/10.1016/j.ijmachtools.2004.11.002 
18. Mirifar Siamak, Kadivar Mohammadali, Azarhoushang Bahman (2020) First steps through intelligent grinding using machine learning via integrated acoustic emission sensors. J Manuf Mater Process 4(2):35. https://www.mdpi.com/2504-4494/4/2/35

19. C H Lee, J Jwo, H Hsieh, C Lin (2020) An intelligent system for grinding wheel condition monitoring based on machining sound and deep learning. IEEE Access 8:58279-58289. https://doi:10.1109/access-2020-2982800

20. Giacomo Bianchi, Marco Leonesio (2019) Hybrid machine learning model-based approach for Intelligent Grinding. I conferenza italiana di robotica e macchine intelligenti(I-RIM2019).

21. Maksoud T M A, Atia M R (2004) Review of intelligent grinding and dressing operations. Mach. Sci. Technol 8(2):263-276. https://doi.org/10.1081/MST-200028748

22. Cai R, Rowe W B, Moruzzi J L, Morgan M N (2007) Intelligent grinding assistant (IGA (C)))-system development part I intelligent grinding database, Int J Adv Manuf Technol 35:75-85. https://doi.org/10.1007/s00170-006-0702-4

23. Shin Y C, Chen Y T, Kumara S (1992) Framework of an intelligent grinding process advisor. J Intell Manuf 3:135-148. https://doi.org/10.1007/BF01477597

24. Pawel Lezanski (2001) An Intelligent system for grinding wheel condition monitoring. Journal of Materials Processing Technology 109(3):258-263. https://doi.org/10.1016/S0924-0136(00)00808-6

25. B W Kruszyński, P Lajmert (2005) An intelligent supervision system for cylindrical traverse grinding. CIRP Annals 54(1):305-308. https://doi.org/10.1016/S0007-8506(07)60109-7

26. W Brian Rowe, Yinnan Chen, J L Moruzzi, B Mills (1997) A generic intelligent control system for grinding. Computer Integrated Manufacturing Systems, 10(3):231-241.

https://doi.org/10.1016/S0951-5240(97)00013-X

27. I Grabec, E Kuljanic (1994) Characterisation of manufacturing processes based upon acoustic emission analysis by neural networks. CIRP Annals 43(1):77-80. https://doi.org/10.1016/S00078506(07)62168-4

28. T Warren Liao (2010) Feature extraction and selection from acoustic emission signals with an application in grinding wheel condition monitoring. Engineering Applications of Artificial Intelligence 23(1):74-84. https://doi.org/10.1016/j.engappai.2009.09.004

29. Kuppuswamy R, Airey K A (2018) Feature extraction on an intelligent polycrystalline diamond insert clock testing method and prediction of product performance. Proceedings of the Institution of Mechanical Engineers, Part E: Journal of Process Mechanical Engineering 232(6):723-733. https://doi.org/10.1177/0954408917738128

30. Zhensheng Yang, Zhonghua Yu, Chao Xie, Youfang Huang (2014) Application of Hilbert-Huang Transform to acoustic emission signal for burn feature extraction in surface grinding process. Measurement 47:14-21. https://doi.org/10.1016/j.measurement.2013.08.036

31. P Sachin Krishnan, K Rameshkumar (2020) Grinding wheel condition prediction with discrete hidden Markov model using acoustic emission signature. Materials Today: Proceedings. https://doi.org/10.1016/j.matpr.2019.12.428 
32. Chen $X$, Limchimchol T (2006) Monitoring grinding wheel redress-life using support vector machines, Int J Autom Comput 3:56-62. https://doi.org/10.1007/s11633-006-0056-2

33. Z Zhao, C Hou, S Duan (2012) Online intelligent monitoring system of grinding process based on process modeling. Second International Conference on Instrumentation, Measurement, Computer, Communication and Control. Harbin-China. https://doi:10.1109/IMCCC.2012.80

34. Asiltürk Ilhan, Tinkir Mustafa, El Monuayri Hazim, Çelik Levent (2012) An intelligent system approach for surface roughness and vibrations prediction in cylindrical grinding. International Journal of Computer Integrated Manufacturing 25(8):750-759. https://doi:10.1080/0951192X.2012.665185

35. Takashi Onishi, Moriaki Sakakura, Takuo Okanoue, Kohei Fujiwara, Yashhiro Fujiyama, Kazuhito Ohashi (2018) Development of the intelligent cylindrical grinding system considering the thermal deformation of a workpiece. Journal of Advanced Mechanical Design, Systems, and Manufacturing 12:5. https://doi.org/10.1299/jamdsm.2018jamdsm0105

36. Jiaqi Jin, Xingyu Jiang, Xinmin Zhang, W Wang (2010) Research on dynamic intelligent control system of grinding quality. 8th World Congress on Intelligent Control and Automation. Jinan-China 2192-2197. https://doi:10.1109/WCICA.2010.5554324

37. W Brian Rowe, Y Li, B Mills, D R Allanson (1996) Application of intelligent CNC in grinding. Computers in Industry 31(1):45-60. https://doi.org/10.1016/0166-3615(96)00036-X

38. I Inasaki, K Okamura (1985) Monitoring of dressing and grinding processes with acoustic emission signals. CIRP Annals 34(1):277-280. https://doi.org/10.1016/S0007-8506(07)61772-7

39. B Karpuschewski, M Wehmeier, I Inasaki (2000) Grinding monitoring system based on power and acoustic emission sensors. CIRP Annals 49(1):235-240. https://doi.org/10.1016/S00078506(07)62936-9

40. T Ling, Y He (2018) Study on New Monitoring of AE Intelligent Grinding. 2nd IEEE Advanced Information Management, Communicates, Electronic and Automation Control Conference (IMCEC), Xi'an 2018:206-209. https://doi:10.1109/IMCEC.2018.8469296

41. X Xie and L Sun (2016) Force control based robotic grinding system and application. 12th World Congress on Intelligent Control and Automation (WCICA), Guilin-China 2016:2552-2555. https://doi:10.1109/WCICA.2016.7578828

42. Y Hatamura, T Nagao, M Mitsuishi, H Tanaka, and K Iwata (1989) Development of a force controlled automatic grinding system for actual NC machining centers. CIRP Annals 38(1):343-346. https://doi.org/10.1016/S0007-8506(07)62719-X

43. Xiaohong Zhang, Weike An, Hui Cao (2012) An expert system of cubic boron nitride (cbn) grinding wheel dressing in cam grinding. Materials and Manufacturing Processes 27(10):1095-1100. https://doi:10.1080/10426914.2011.654167

44. B Varghese, S Pathare, R Gao, C Guo, S Malkin (2000) Development of a sensor-integrated 'intelligent' grinding wheel for in-process monitoring. CIRP Annals 49(1,):231-234. https://doi.org/10.1016/S0007-8506(07)62935-7 
45. I Inasaki (1999) Sensor fusion for monitoring and controlling grinding processes. Int J Adv Manuf Technol 15:730-736. https://doi.org/10.1007/s001700050125

46. Cai R, Morgen M N (2007) Development of intelligent grinding database. Key Engineering Materials 329:21-26. https://doi:10.4028/www.scientific.net/kem.329.21

47. Jacso A, Matyasi G, Szalay $T$ (2019) The fast constant engagement offsetting method for generating milling tool paths. Int J Adv Manuf Technol 103:4293-4305. https://doi.org/10.1007/s00170-019-03834-8

48. Karadogan A, Kahriman A, Ozer U (2008) Application of fuzzy set theory in the selection of underground mining method. J S Afr Inst Min metall 108(2):73-79.

http://www.scielo.org.za/scielo.php?script=sci_arttext\&pid=S2225$62532008000200002 \& \operatorname{lng}=e n \& n r m=$ iso

49. B Liang, S D Iwnicki, Y Zhao (2013) Application of power spectrum, cepstrum, higher order spectrum and neural network analyses for induction motor fault diagnosis. Mechanical Systems and Signal Processing 39(1-2):342-360. https://doi.org/10.1016/j.ymssp.2013.02.016

50. Kunpeng Zhu, Yoke San Wong, Geok Soon Hong (2009) Wavelet analysis of sensor signals for tool condition monitoring: a review and some new results. International Journal of Machine Tools and Manufacture 49(7-8):537-553. https://doi.org/10.1016/j.ijmachtools.2009.02.003

51. Chen X, Limchimchol T (2006) Monitoring grinding wheel redress-life using support vector machines. Int J Automat Comput 3:56-62. https://doi.org/10.1007/s11633-006-0056-2

52. A Arun, K Rameshkumar, D Unnikrishnan, A Sumesh (2018) Tool condition monitoring of cylindrical grinding process using acoustic emission sensor. Materials Today: Proceedings 5(5):11888-11899. https://doi.org/10.1016/j.matpr.2018.02.162

53. Yang Z, Yu Z (2012) Grinding wheel wear monitoring based on wavelet analysis and support vector machine. Int J Adv Manuf Technol 62:107-121. https://doi.org/10.1007/s00170-011-3797-1

54. Sanidhya Painuli, M Elangovan, V Sugumaran (2014) Tool condition monitoring using K-star algorithm. Expert System with Applications 41(6):2638-2643. https://doi.org/10.1016/j.eswa.2013.11.005

55. Ananad Jaitha (2017) An introduction to bayesian network theory and usage. Dissertation, Claremont College. https://publications.idiap.ch/downloads/reports/2000/rr00-03.pdf

56. Mohmmad Hanafy, Hoda Elmaraghy (2017) Integrated products-systems design environment using Bayesian networks. International Journal of Computer Integrated Manufacturing 30(7):708-723. https://doi:10.1080/0951192X.2015.1099072

\section{Figures}




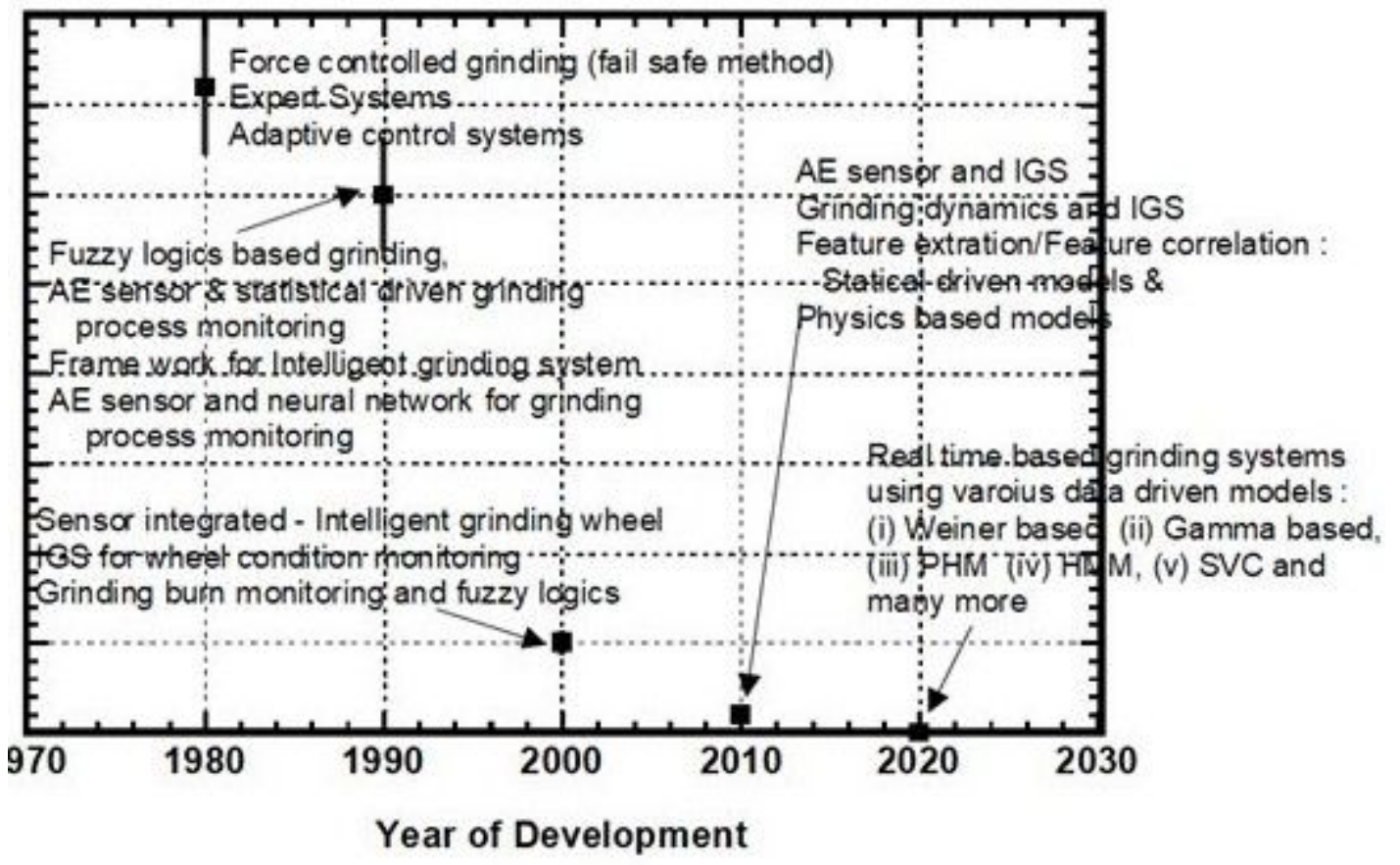

\section{Figure 1}

Growth phase of Intelligent Grinding System development with emphasis to response time for correction 
Intelligent grinding system built using experimental findings/empirical relations
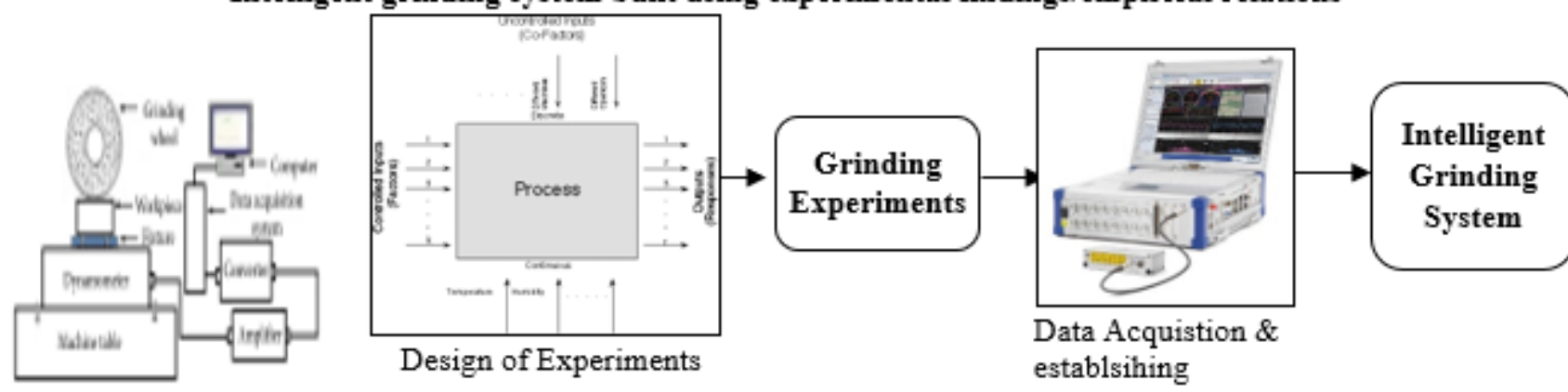

Data Acquistion \& establsihing grinding process relations

Intelligent grinding system built using analytical models
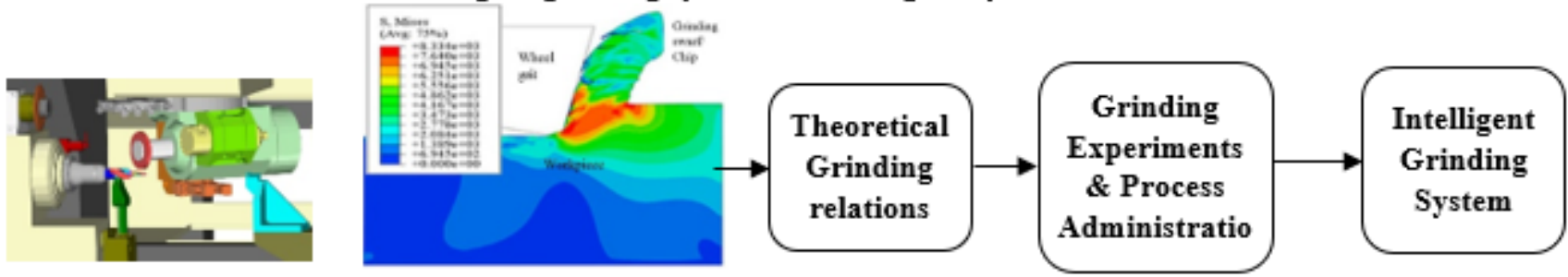

Grinding science behaviour

Intelligent grinding system built Fuzzy based models
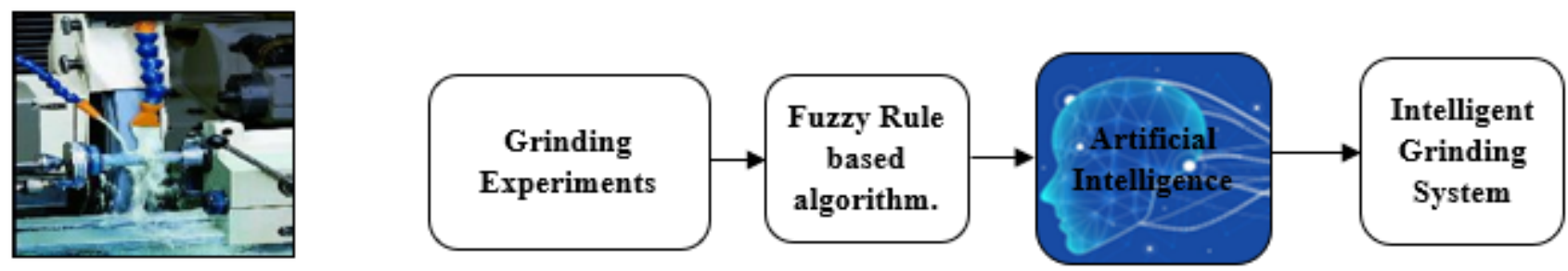

Intelligent grinding system built Neural network
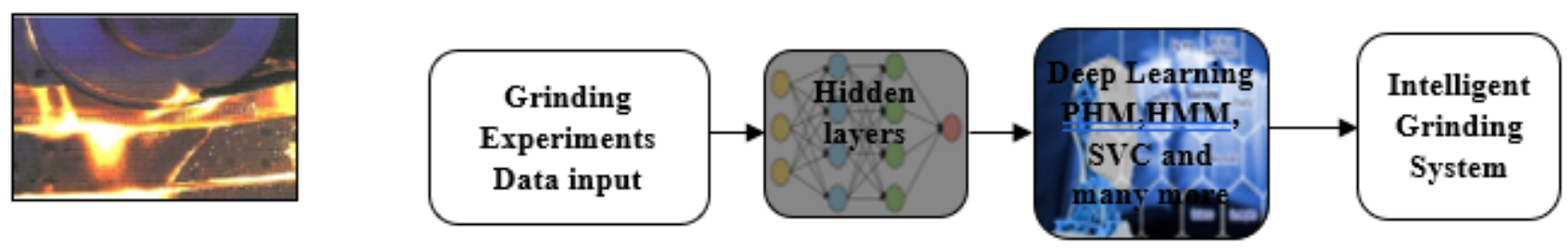

Figure 2

Intelligent grinding system built with different strategies. 


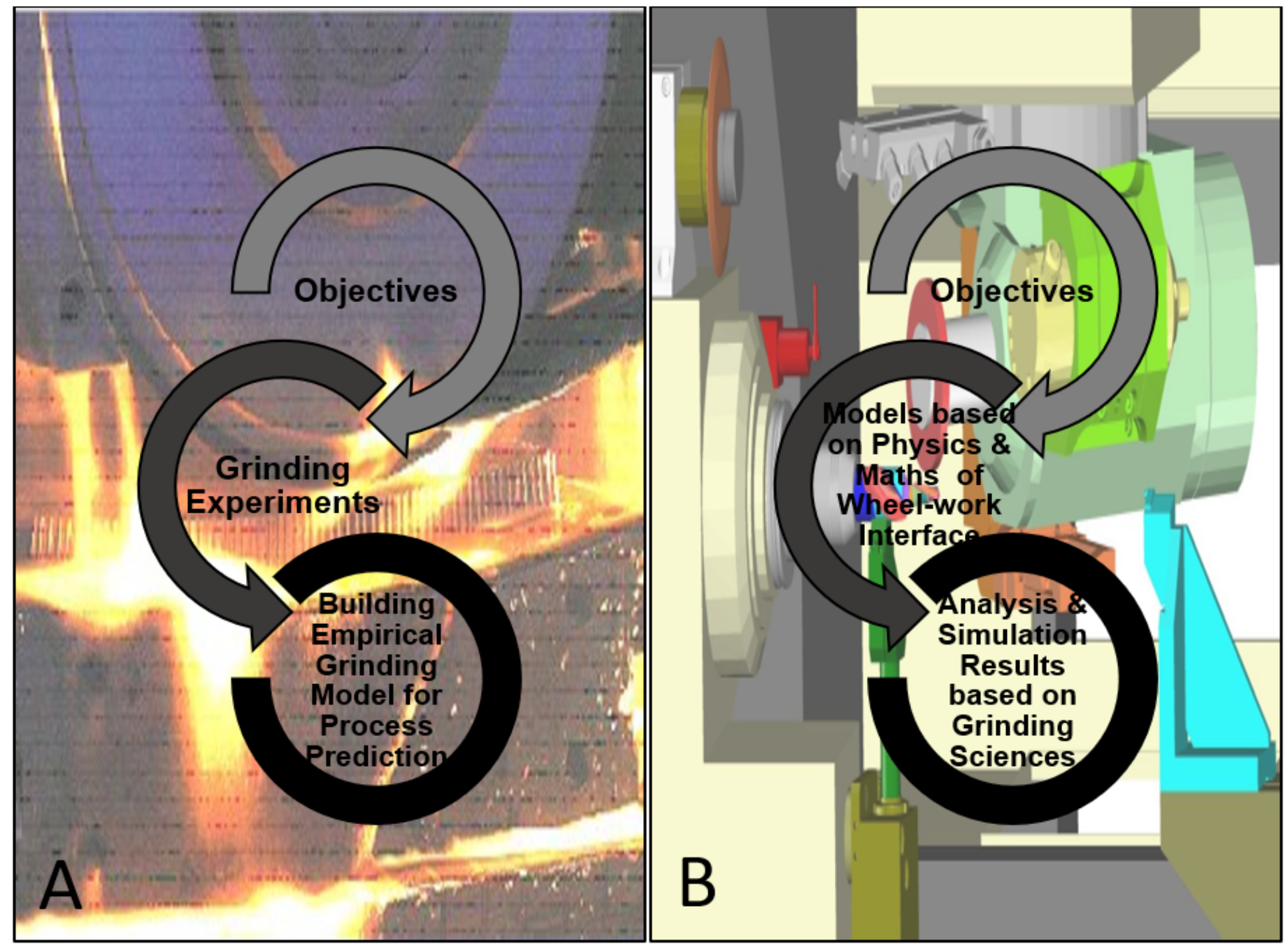

Figure 3

Grinding models preparations algorithm A) Experimental based grinding models B) Analysis and Simulation based grinding model. 

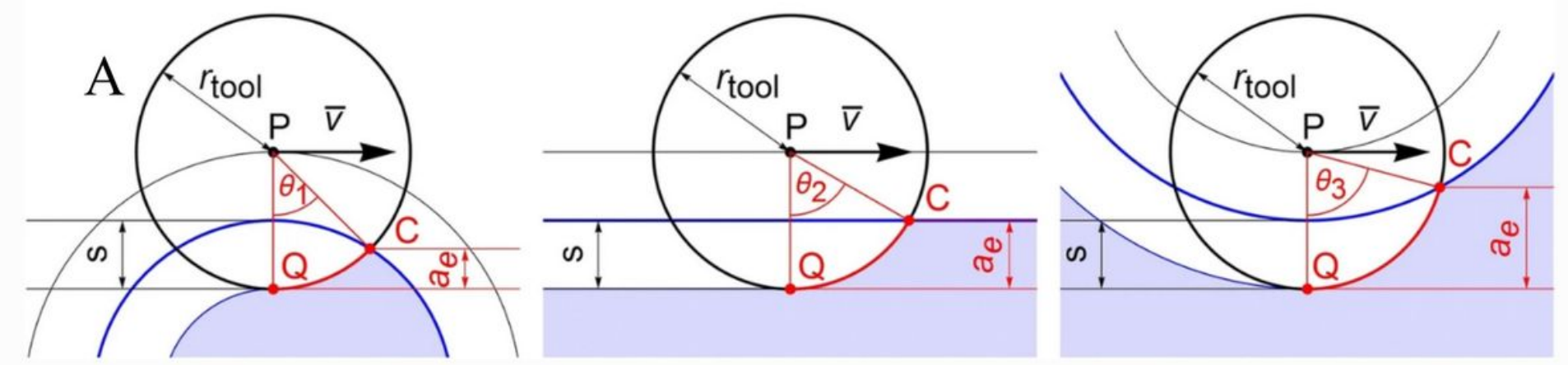

$\mathrm{B}$

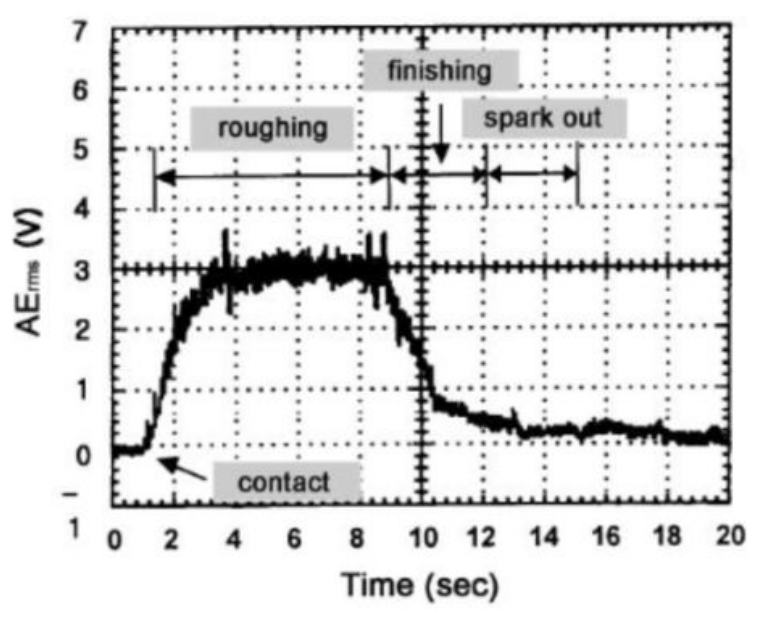

(a) Normal state

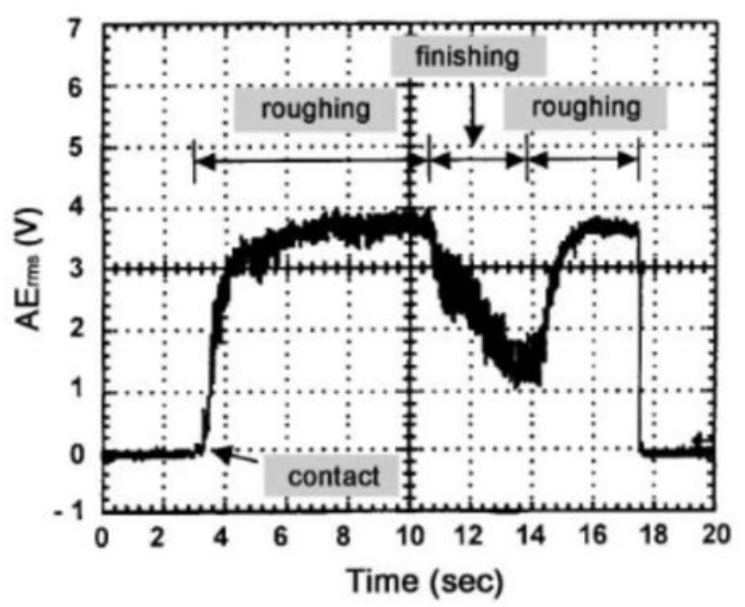

(b) Abnormal state

Figure 4

(A) Chip thickness variation in machining depending on the tool path position and (B) Typical AErms signal for a normal state and abnormal state of grinding. 
(A)
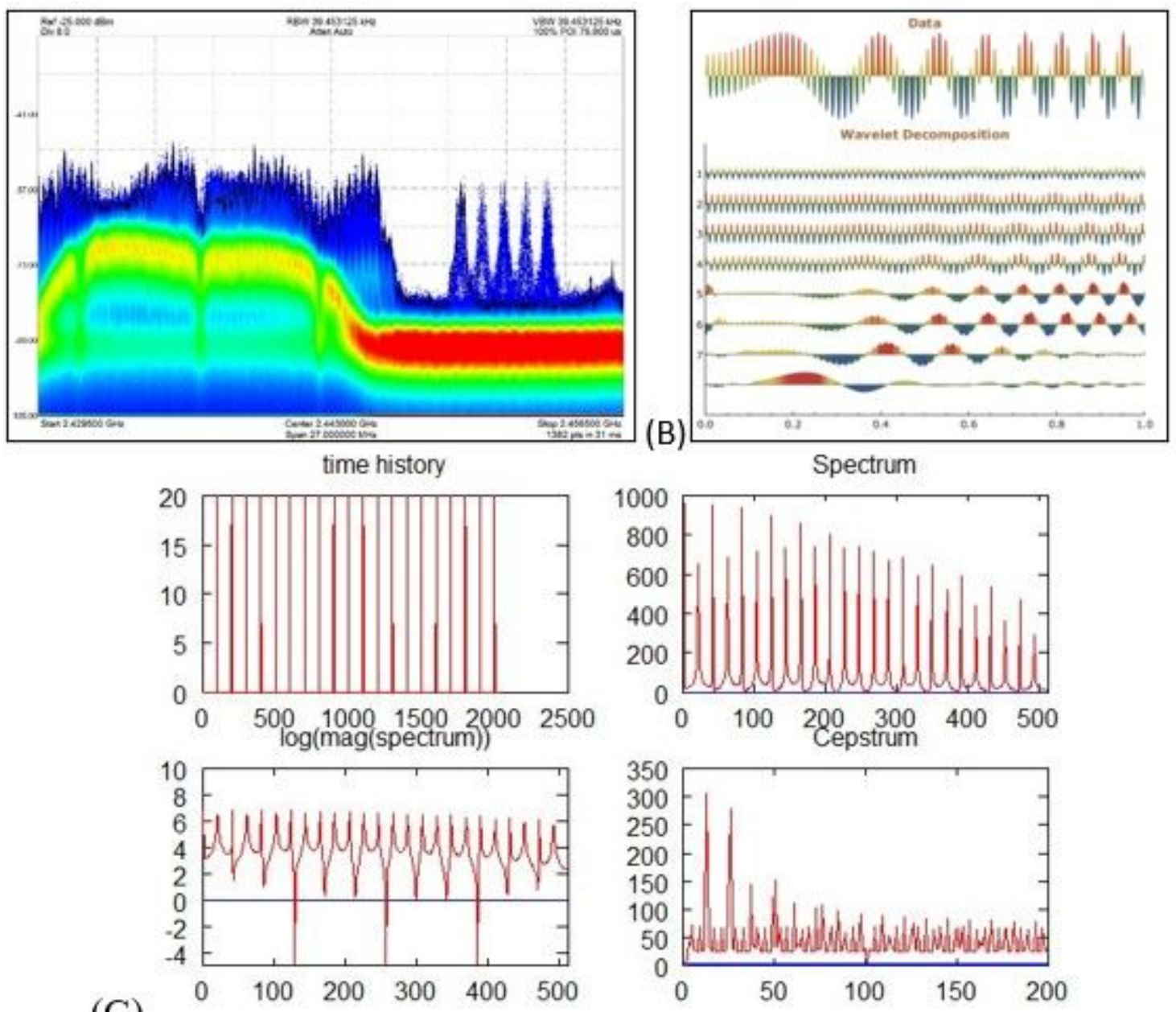

(C)

\section{Figure 5}

Typical wheel-work interface output of (A) Spectrum analysis, (B) wavelet analysis and (C) Cepstrum analysis 


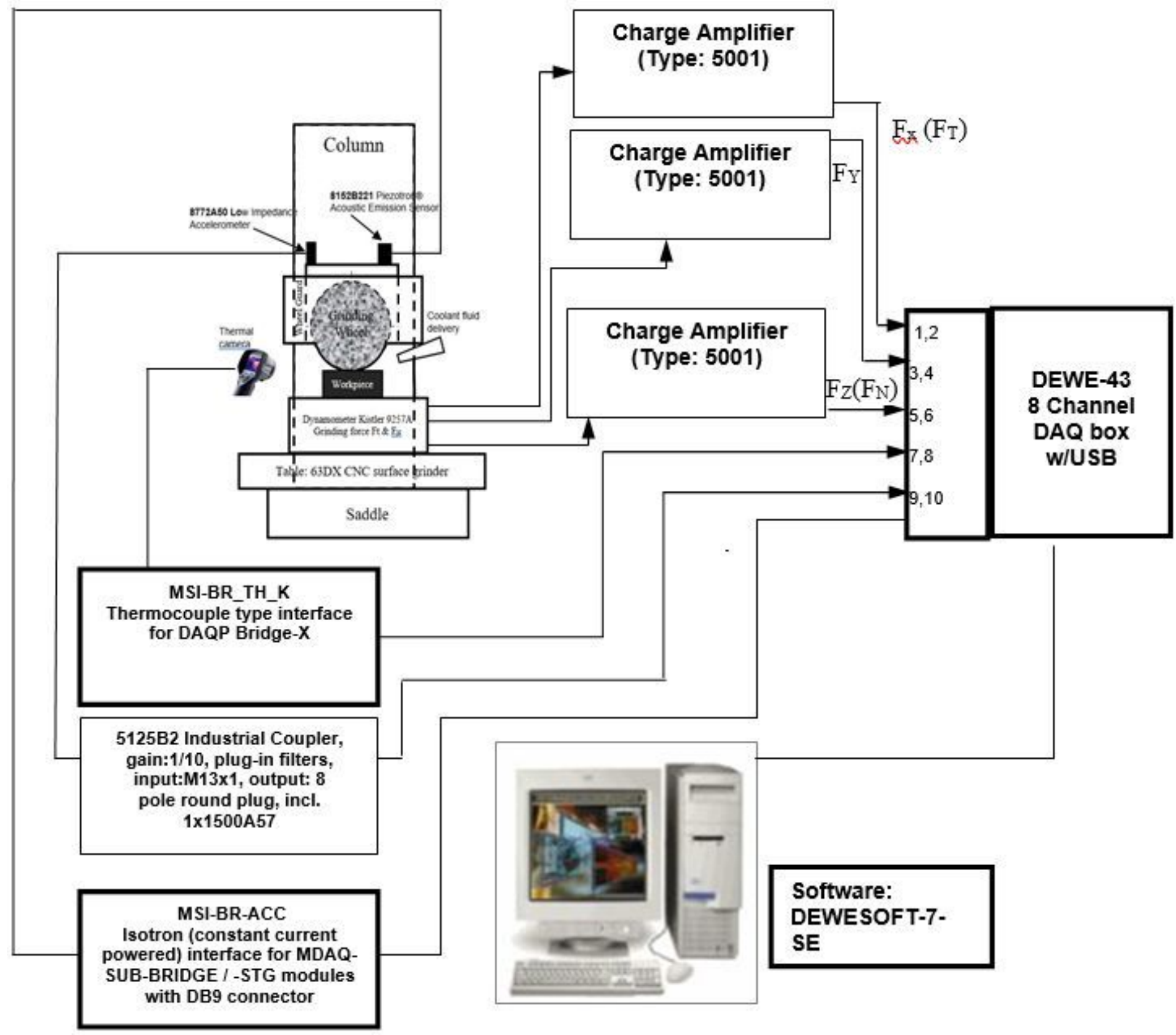

Figure 6

Feature extraction-grinding experiments and integration to the DAQ system. 


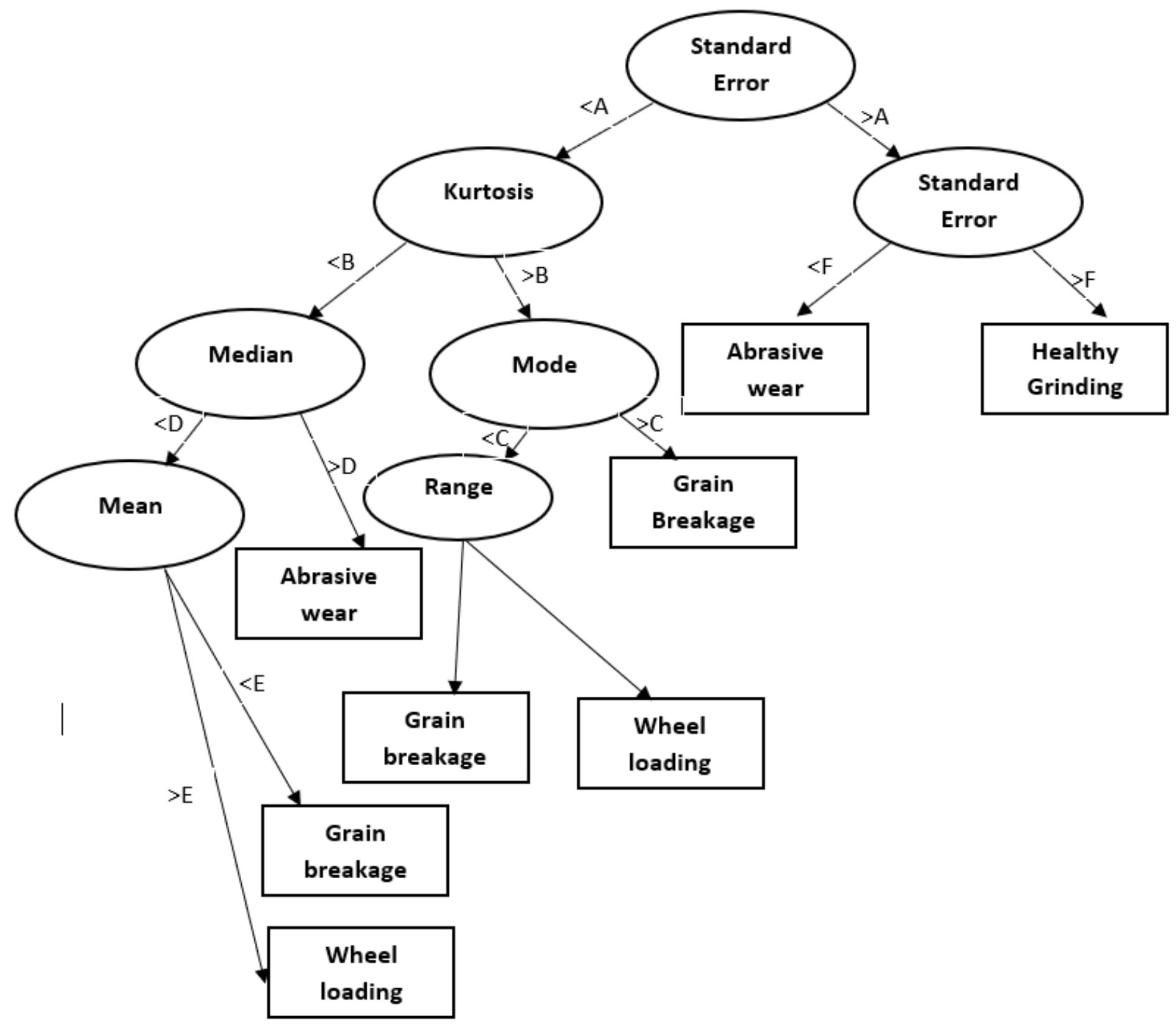

Figure 7

Decision tree feature of AErms signal for a typical grinding wheel-work interface 


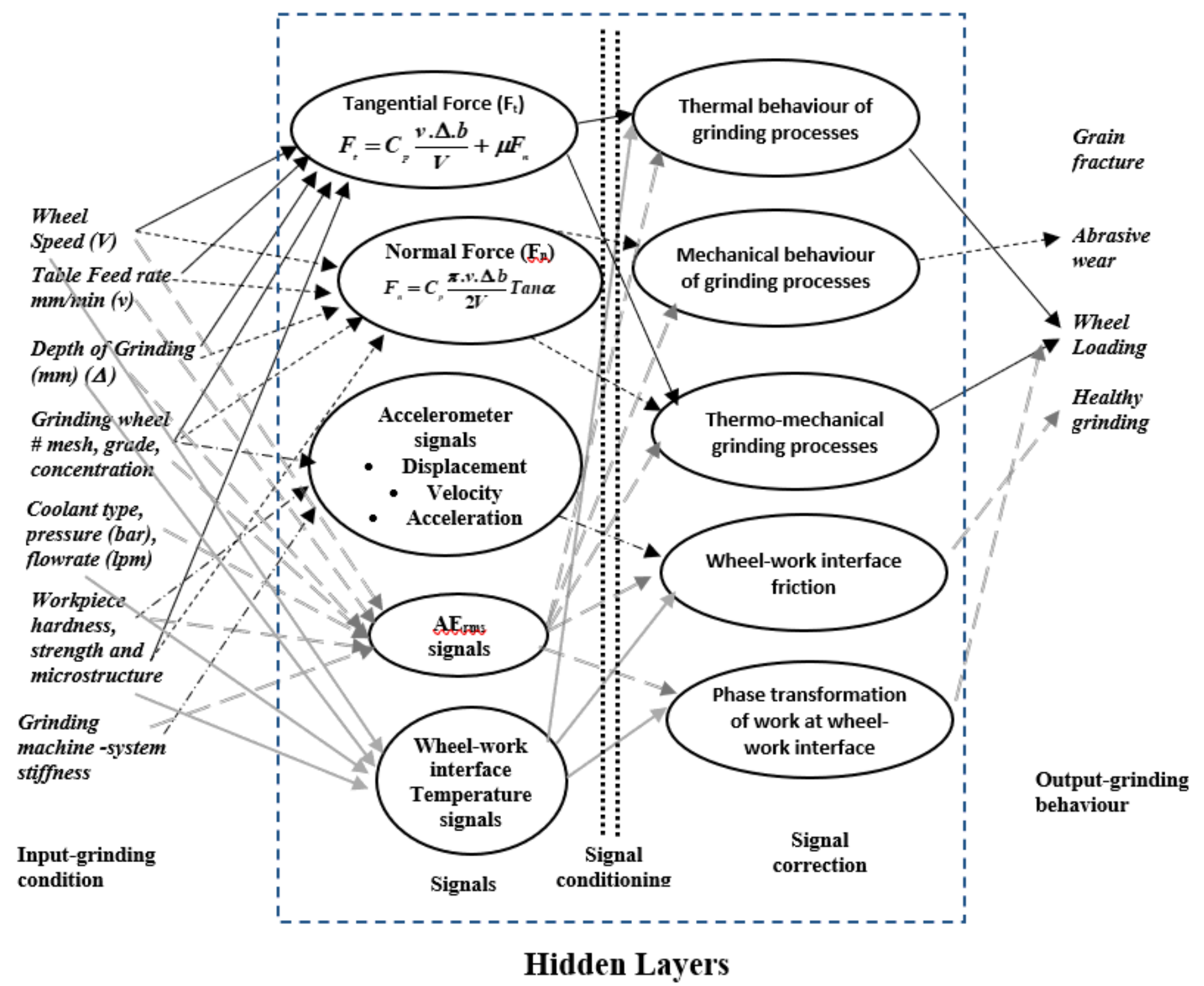

Figure 8

Grinding wheel failure architecture using ANN for the break-in-tests. 